\title{
PEMINJAMAN KEBIJAKAN (POLICY BORROWING) UNTUK PERENCANAAN PENDIDIKAN
}

\author{
Ebni Sholikhah \\ Program Studi Kebijakan Pendidikan, Universitas Negeri Yogyakarta \\ Ebnisholikhah@uny.ac.id
}

\begin{abstract}
Abstrak
Peminjaman kebijakan merupakan bagian dari studi komparasi pendidikan. Meminjam kebijakan dari negara lain menjadi hal biasa di era globalisasi untuk merencanakan pendidikan di suatu negara. Hanya saja, tidak semua ekspektasi atas keberhasilan kebijakan yang diadopsi dari negara lain mampu di capai negara peminjam. Kebijakan baru yang disusun mungkin malah mengandung dan mengundang masalah baru. Artikel ini menggambarkan tentang peminjaman kebijakan dalam perencanaan pendidikan. Beberapa hal yang tercakup antara lain sejarah peminjaman kebijakan, peminjaman kebijakan dalam konteks perencanaan pendidikan, dan faktor-faktor yang mempengaruhi keberhasilan peminjaman kebijakan.
\end{abstract}

Kata Kunci: Peminjaman Kebijakan (Policy Borrowing), Pendidikan Komparatif, Perencanaan Pendidikan

\begin{abstract}
Policy borrowing is part of an educational comparative study. Borrowing policies from other countries is common in the era of globalization to educational planning in a country. However, not all expectations for the success of policies adopted from other countries can be achieved by the borrowing country. The latest compiled policies may instead contain and invite new issues. This article describes the policy borrowing in education planning. Some of the items covered include the history of policy borrowing, policy borrowing in the context of educational planning, and the factors affecting the success of policy borrowing.
\end{abstract}

Keywords: Policy Borrowing, Education Policy, Comparative Education

\section{PENDAHULUAN}

Setiap negara tentu tidak bisa bertahan tanpa adanya hubungan kerjasama dengan negara lain. Hubungan tersebut dapat berbentuk bilateral maupun multilateral yang mencakup berbagai bidang seperti politik, sosial, hokum dan keamanan, ekonomi perdagangan, maupun pendidikan. Kerjasama antar negara biasanya diakomodir melalui forum-forum internasional yang 
dibentuk sesuai dengan maksud dan tujuannya masing-masing. Salah satu contoh forum internasional dalam bidang pendidikan yakni Southeast Asian Ministers of Education Organization (SEAMEO) atau organisasi kementerian pendidikan se Asia Tenggara. Visinya yakni untuk saling memahani dan bekerjasama dalam bidang pendidikan, ilmu, dan kebudayaan. Dengan motto "Leading through Learning" setiap anggota diharapkan saling bekerjasama dan juga saling belajar untuk memajukan pendidikan dan kualitas hidup bangsa Asia Tenggara. SEAMEO merupakan kesempatan bagi Indonesia untuk mengadopsi dan mengembangkan gagasan serta kebijakan pendidikan yang dimiliki oleh negara lain di kawasan Asia Tenggara (Anies Baswedan, 16/11/2015).

Secara konseptual, kegiatan memahami dan mempelajari pendidikan dari luar negara masuk dalam kajian pendidikan komparatif. Bidang studi ini mengkaji upaya untuk melihat dan memahami kehidupan pendidikan dinegara lain untuk memperluas pandangan terhadap sistem pendidikannya agar tidak terjabak pada egosentrisme sempit. Edmund J. King (1986) melihat bahwa pendidikan komparatif menjadi salah satu instrumen yang dapat digunakan dalam merencanakan pendidikan. Oleh karenanya untuk memajukan sistem pendidikan di suatu negara, maka belajar dari negara lain bukanlah hal yang mustahil.

Sistem pendidikan negara lain dapat diadopsi dan diadaptasi sesuai kepentingan negara atau disebut juga sebagai peminjaman kebijakan (policy borrowing). David Rafee (2011) menyatakan bahwa policy-makers biasanya tertarik belajar tentang sistem pendidikan dari pengalaman negara lain, terutama dari negara yang dipercaya telah berhasil. Beberapa kebijakan pendidikan di berbagai negara juga merupakan hasil dari meminjam. Sebagai contoh, kebijakan New Senior Secondary (NSS) Hong Kong meminjam International Baccalaureate Diploma Programme curriculum (IBDP) yang dikembangkan Switzerland (Anthony Chow, 2014). Bahkan politisi British rutin melakukan tur ke negara-negara tetangganya di Eropa untuk menggali ide-ide pendidikan untuk dikaji dan dimanfaatkan negaranya. Mereka 
meminjam sistem pendidikan anak usia dini "Sure Start" dari Amerika. Namun demikian, Amerika Serikat dianggap sebagai salah satu negara skeptic yang tak mau belajar dari negara lain (theatlantic.com, 26/10 2015).

Bukan hanya negara maju saja yang penasaran dengan ide-ide kebijakan dari negara lain, namun biasanya merencanakan kebijakan dengan mengadopsi kebijakan dari negara lain juga dilakukan oleh negara berkembang. Hal ini disebabkan karena negara maju dianggap sudah sukses dalam penyelenggaraan pendidikannya, sehingga negara berkembang termotivasi untuk mengikuti kesuksesan tersebut. Alasan lain karena fenomena globalisasi sebagai bentuk deterritorialisastion (Steiner-Khamsi, 2012) berbagai bidang sehingga menunjang riset-riset pendidikan komparatif untuk mempelajari keberhasilan sistem pendidikan negara lain. Contoh negara berkembang yang meminjam kebijakan pendidikan negara maju misalnya, Indonesia meminjam kebijakan bantuan pendidikan bersyarat dari Brazil dan Vietnam yang meminjam kebijakan Common European Framework of Reference (CEFR) for language untuk diterapkan pada universitas-universitas di Vietnam (Huy dan Hamid, 2015).

Proses meminjam kebijakan pendidikan negara lain memiliki manfaat untuk memberikan referensi alternatif solusi terhadap permasalahan yang dihadapi suatu negara. Patton and Sawicki (1987) menyebutkan bahwa belajar dari pengalaman nyata yang dilakukan negara lain dapat menjadi salah satu cara untuk merencanakan kebijakan disuatu negara. Namun demikian, mengadopsi kebijakan yang sudah diterapkan di negara lain dan dianggap sukses ternyata tidak semudah yang kita bayangkan. Terdapat beberapa pertimbangan sebelum menerapkan kebijakan tersebut baik dari proses perencanaan sampai dengan implementasinya. Tulisan ini menyajikan konsep meminjam kebijakan pendidikan dan hal-hal lain yang berkaitan dengannya seperti sejarah peminjaman kebijakan, peminjaman kebijakan dari perspektif perencanaan pendidikan, dan faktor-faktor yang mempengaruhi keberhasilan peminjaman kebijakan. 


\section{PEMBAHASAN}

\section{Sejarah "policy borrowing"}

Istilah education policy borrowing sudah sejak lama muncul yang dulu dikenal dengan education borrowing. Education borrowing dapat ditelusuri sejak abad ke 18 (tepatnya 1817), ketika Antoine Jullien de Paris mulai merintis studi komparasi pendidikan yang sekarang menjadi bidang ilmu pendidikan komparatif. Tujuan utama dari penyelidikan pendidikan komparatif untuk mengidentifikasi dan menerapkan "good practice" pendidikan di negara sendiri. Saat itu tahap yang pertama kali muncul dalam studi komparasi adalah "borrowing" sampai tahun 1930-an. Setelah itu disusul dua tahap perkembangan studi komparasi lainnya yang disebut tahap predicting (1930an-1960an) dan analyzing (1960an-1990an). Pada tahap borrowing, tujuan utamanya adalah untuk memahami sistem pendidikan luar negeri dan mencari yang terbaik untuk dapat diterapkan.

Menurut Arif Rohman (2010: 95), suatu negara yang ingin membangun dan memperbaiki sistem pendidikannya dapat melihat dan mengadopsi sistem pendidikan negara lain yang dianggap lebih baik. Education borrowing menarik bagi para policymaker karena dapat mereduksi resiko dan ketidakpastian kegagalan jika membuat kebijakan yang benar-benar baru.

Pada abad 19an sistem pendidikan yang dianggap baik adalah Prusia (German). Selama abad 19an, German telah menjadi negara yang meminjami sistem pendidikannya ke negara lain. Salah satu daya tarik German yakni telah mengembangkan embrio sistem pendidikan wajib pada abad 18an, jauh sebelum negara maju lainnya. Sehingga tidak mengherankan jika negara lain harus melihat lebih dekat lagi tentang sistem pendidikan yang diterapkannya. Daya tarik lainnya terletak pada fungsi negara yang tepat dalam membuat kebijakan tentang tingkat kehadiran disekolah (denda bagi orang tua yang anaknya tidak hadir), penentuan kurikulum, penanganan masalah pendidikan agama, dan pendidikan guru. 
Namun demikian, seiring berkembangnya peradaban, sistem pendidikan di German dapat dilihat dari dua sisi yakni positif atau negative, sebagai perwujudan cita-cita yang harus dirunut atau dihindari (Philips dan Schweisfurth, 2014: 44). Hal ini dapat dilihat dari perkembangan pendidikan di German. Bertahun-tahun pendidikan menengah German dianggap paling efektif dengan hasil yang membanggakan, namun hasil pengukuran internasional PISA pada tahun 2000 menunjukkan nilainya dibawah rata-rata negara peserta pengukuran. Fenomena ini menjadi refleksi bahwa pengadopsian kebijakan pendidikan dari suatu wilayah tidak dapat dilakukan sepanjang masa. Keberhasilan suatu sistem pendidikan tidak selalu berlaku seterusnya karena selalu ada dinamika yang melatarbelakangi keberhasilan maupun kegagalannya sesuai konteks kewilayahan.

Pada masa "borrowing" untuk mendapatkan informasi dari wilayah lain, para tokoh pada saat itu lebih menekankan pada paradigma positivist dengan pendekatan scientific. Temuan dari metode itu biasa ditampilkan dalam pentuk tabel atau daftar sistem yang dianggap terbaik. Terdapat keuntungan menggunakan metode ini, terutama untuk para policymaker yang ingin segera memperbaiki sistem pendidikannya secara praktis. Namun beberapa kritik kemudian muncul berkenaan dengan pendekatan dalam mempelajari sistem pendidikan luar negeri tanpa diikuti pencermatan terhadap konteks lingkungan negara. Sebuah kebijakan yang dianggap baik di suatu negara mungkin tidak tepat diterapkan di negara lain karena perbedaan kontekstual (Anthony Chow, 2014). Terkait dengan kritikan ini Durkheim (dalam Arif Rohman, 2010) juga menyatakan bahwa "tidak ada satu tipe ideal pendidikan bagi semua manusia. Karena pendidikan sangat berkait erat dengan keadaan sosio-kultural masyarakat. Kritikan ini kemudian dikenal dengan paradigma interpretivist.

Atas kritik diatas, sejarah tahapan pendidikan komparatif beralih ke tahap masa selanjutnya yakni predicting. Usaha perbaikan pendidikan tidak lagi dilakukan secara mentah-mentah mengadopsi pendidikan luar 
negeri, namun juga disertai pertimbangan kemungkinan keberhasilan dan kegagalannya.

\section{Lingkup "Policy Borrowing"}

Terkadang kita terjebak pada asumsi yang menyatakan bahwa disebut policy borrowing atau policy transfer jika kita mengambil dan menerapkan kebijakan dalam perspektif yang sempit. Perspektif sempit yang dimaksud ialah meminjam kebijakan hanya berasal dari lingkup negara. Padahal, meminjam kebijakan bukan hanya terbatas dari kebijakan negara. Dolowitz and Marsh (2000) menyatakan bahwa dalam policy borrowing para pembuat kebijakan dapat melihat dari tiga sumber berjenjang yakni level internasional, nasional, dan lokal. Lingkup internasional berarti sebuah negara dapat belajar dari sistem politik lain dalam level internasional. Bukan hanya terbatas pada pendidikan yang diterapkan negara lain untuk diadopsi, namun juga kebijakan lembagalembaga internasional seperti UNESCO, UNICEF dsb yang dapat diratifikasi.

Pada lingkup nasional, policymaker dapat melakukan adopsi kebijakan dari unit pemerintah lain dalam lingkup negara. Misalnya, kementerian pendidikan mengadaptasi kebijakan kementerian sosial atau kementerian lainnya. Pada lingkup lokal, policymaker dapat belajar dari kebijakan yang diterapkan oleh pemerintahan level lokal, sehingga unit lokal dapat memberikan contoh untuk tingkat nasional. Biasanya lingkup negara mempelajari sistem pendidikan negara lain tetapi dapat juga belajar dari negara bagian atau unit pemerintahan local negara sendiri maupun negara lain.

Terkait macam-macam bentuk transfer kebijakan, Dolowitz and Marsh (2000) menyampaikan bahwa terdapat empat macam tingkatan yang berbeda dalam transfer kebijakan. Pertama copying, mencakup adopsi langsung dan menyeluruh. Negara meniru secara mutlak kebijakan yang telah diterapkan wilayah lain. Kedua emulation, menyangkut transfer 
ide-ide dibalik kebijakan atau program. Negara hanya belajar tentang idea tau gagasan yang melatarbelakangi kebijakan yang diterapkan wilayah lain, sehingga masih terdapat celah untuk melakukan modifikasi dalam merealisasaikan ide-ide tersebut.

Ketiga combinations, menyangkut pencampuran beberapa kebijakan. Beberapa kebijakan yang berbeda baik dari suatu wilayah maupun beberapa wilayah yang berbeda disintesiskan untuk diterapkan di wilayah sendiri. Semakin beragam informasi dan pengalaman kebijakan yang didapatkan dari berbagai wilayah maka semakin banyak ide yang didapatkan untuk merencanakan kebijakan di wilayah sendiri. Keempat inspiration, yakni kebijakan di wilayah lain hanya menjadi inspirasi untuk melakukan perubahan. Kebijakan yang telah berhasil diterapkan diwilayah lain mengilhami dibentuknya kebijakan di wilayah sendiri. Harapannya, hasil penerapan tersebut akan sama suksesnya dengan kebijakan yang diadopsi. Hanya saja kebijakan yang diterapkan tidak selalu dapat menunjukkan hasil yang sama dengan kebijakan aslinya.

\section{Policy Borrowing dalam rangka perencanaan pendidikan}

Peminjaman kebijakan dalam perencanaan pendidikan dapat dirunut dari dua perspektif yang berbeda namun saling melengkapi, yakni perspektif ilmu kebijakan dan ilmu komparasi pendidikan (pendidikan komparatif). Pertama, dalam perspektif kebijakan, pendidikan saat ini lebih bersifat structural fungsional dimana diatur oleh pemerintah atas nama negara melalui kebijakan. Kebijakan dapat diterapkan manakala telah melalui proses formulasi kebijakan. Para policymaker telah memformulasikan kebijakan sedemikan rupa agar tujuan pendidikan dapat dicapai. Formulasi kebijakan merupakan tahap awal yang didalamnya terdapat beberapa aktivitas, antara lain perumusan masalah, identifikasi alternatif solusi, dan rekomendasi. Formulasi kebijakan inilah yang sering diartikan sama dengan perencanaan kebijakan. Fungsinya adalah sebagai acuan untuk pelaksanaan maupun pengawasan. 
Menurut Manap Somantri (2013) perencanaan memiliki unsure kegiatan mengidentifikasi, menginventarisasi, dan menyeleksi kebutuhan berdasarkan skala prioritas, mengadakan spesifikasi yang lebih rinci mengenai hasil yang akan dicapai, mengidentifikasi persyaratan atau criteria untuk memenuhi setiap kebutuhan, serta mengidentifikasi kemungkinan alternatif, strategi, dan sasaran bagi pelaksanaannya. Perencanaan menjadi penting untuk mempersiapkan pelaksanaan kebijakan agar terhindar dari kekeliruan atau kesalahan dimasa depan. Oleh karena itu perencanaan harus disusun secara komprehensif dan visioner agar kebijakan yang dihasilkan sedapat mungkin responsive terhadap dinamika problem sosial.

Kebijakan yang efektif ditentukan oleh alternatif-alternatif kebijakan yang baik. Patton, Sawicki, and Clark (2016) dalam bukunya yang berjudul Basic Methods of Policy Analysis and Planning menyatakan bahwa salah satu cara cara untuk menggali alternatif kebijakan ialah dengan belajar dari pengalaman nyata (comparison of real-worlds experiences). Ini merupakan metode yang dapat digunakan untuk menggali alternatif kebijakan nyata yang telah digunakan pihak lain sebagai cara mengatasi masalah, terutama pada wilayah yang memiliki kesamaan setting sosial. Tujuan utama metode ini bukan untuk mencari alternatif yang dianggap paling baik, namun lebih menekankan pada pengalaman wilayah lain dalam mengimplementasikan suatu kebijakan (AG. Subarsono, 2013: 56). Singkatnya, suatu wilayah dapat merencanakan kebijakan pendidikan berkaca dari kesuksesan pengimplementasian kebijakan di wilayah lain.

Alternatif yang telah dipilih dan digunakan oleh wilayah lain merupakan ide yang berharga dan mungkin kebermanfaatannya akan jauh meningkat ketika diadopsi di wilayah sendiri. Kebermanfaatan tersebut terlihat ketika telah dimodifikasi, mengidentifikasi actor-aktor yang mendukung maupun menentangnya, dan mempertimbangkan bagaimana nasib keberhasilan kebijakan itu. Memperoleh informasi ini dapat menjadi 
keuntungan besar karena telah melalui langkah dasar yang terdapat pada metode lain sehingga waktu untuk menganalisis alternatif kebijakan lebih cepat. Disisi lain, manfaat besar yang didapatkan ketika menggunakan metode ini dalam perencanaan pendidikan adalah berkurangnya resiko kegagalan. Kebijakan yang dianggap sukses telah disesuaikan dengan kondisi wilayah sendiri sehingga resiko kegagalan dapat ditekan.

Seperti yang dicontohkan pada subbab sebelumnya bahwa hampir setiap negara belajar dari negara lain dalam merencanakan pendidikan, salah satunya Indonesia. Hampir seluruh kebijakan pendidikan di Indonesia merupakan pinjaman (policy borrowing); yaitu belajar dari luar dan menggunakan untuk memperbaiki situasi di dalam (Mulyo Prabowo 2010). Pemerintah juga gemar berkeliling dunia dalam rangka mempelajari sistem pendidikan negara lain. Namun bukan hanya negara berkembang seperti Indonesia saja yang gemar berkeliling dunia belajar dari negara lain. Negara maju seperti Inggris dan Jepang pun demikian. Kemajuan yang mereka dapat bukan hanya hasil pemikiran inovatif pribadi, namun juga dari upaya mereka sejak lama untuk memperlajari sistem pendidikan negara lain. Sejak restorasi Meiji, Jepang yang diwakili oleh Iwakura telah bekeliling dunia dan mengeksplore kondisi pendidikan di Amerika Serikat (Phillips and Schweisfurth, 2014: 43). Begitu juga Inggris yang sampai saat ini masih selalu haus dengan perkembangan pendidikan yang terjadi di negara-negara tentanggannya. Mereka begitu penasaran dengan keberhasilan yang dicapai negara lain sehingga berkeinginan untuk mengikuti capaian tersebut melalui adopsi kebijakannya (Tierney, 2015).

Kedua, policy borrowing dapat dikaji dari perspektif ilmu komparasi pendidikan (pendidikan komparatif) yang membandingkan pendidikan antar wilayah untuk memformulasikan kebijakan pendidikan di wilayah sendiri. Hal ini dapat dicermati dari konsep-konsep policy borrowing dari sudut pandang perencanaan yang dikemukakan oleh tokoh pendidikan komparatif. Salah satu tokoh yang melihat komparasi 
pendidikan dari perspektif perencanaan adalah Edmund J. King (1968: 162). Ia menyatakan bahwa

"Comparative studies are the very essence of the continuing enquiry that modern education is seen to be, with no false division between research and experiment ... this way can a continuous decision-making process be established".

(Studi komparasi merupakan kegiatan pokok atas kelanjutan dari kegiatan penyelidikan untuk melihat pendidikan modern saat ini, dengan tanpa memisahkan antara penelitian dan eksperimen ... cara ini dapat dilanjutkan menjadi proses pengambilan keputusan)

Menurutnya, saat ini tidak sulit untuk menemukan solusi atas masalah pendidikan atau masalah sosial di suatu negara. Kita bisa melihat solusi tersebut dari negara, kebudayaan, dan lingkungan sosial yang lain. Kebijakan yang canangkan negara lain mungkin mengandung solusi atas permasalahan yang dialami negara sendiri karena mungkin memiliki kesamaan latar belakang sosial. Oleh karena itu King menyatakan bahwa mengomparasikan pendidikan dengan negara lain dapat menggali potensi solusi masalah yang dialami. Sistem pendidikan maupun kebijakan yang telah diterapkan wilayah lain diteliti dan ditelaah sehingga menghasilkan rekomendasi yang dapat dipertimbangkan untuk merencanakan kebijakan diwilayah sendiri.

Philips dan Ochs (2003) mengatakan "If one of the principal aims of comparative education is to 'learn lessons' from the experience 'elsewhere', we need to know what lessons are being learned and in which ways". (jika salah satu tujuan utama komparasi pendidikan adalah untuk 'belajar' pengalaman dari wilayah 'lain', kita perlu mengetahui pelajaran apa yang akan di kaji dan dengan 'cara' yang mana). Padangannya memperluas kajian komparasi pendidikan bukan hanya untuk merencakan, namun juga sampai pada strategi yang dapat dilakukan setelah menelaah sistem pendidikan wilayah lain. Melalui pandangan yang didapat dari wilayah lain, suatu negara dapat merencanakan pendidikan tanpa meninggalkan penyesuaian yang kritis. Stategi yang dapat dilakukan tidak harus mutlak meniru wilayah lain, namun harus menyesuaikan dengan 
karakteristik lingkungan sosial yang ada. Tanpa ada pertimbangan penyesuaian, peluang kegagalan terbuka lebar. Akhirnya, bukan menyelesaikan masalah tetapi malah memunculkan masalah baru.

Kedua perspektif diatas meskipun terlihat terpisah, namun keaannya saling mengisi. Indonesia sebagai negara hukum, menyelenggarakan pendidikan melalui kerangka kebijakan. jika dipandang dari perspektif kebijakan maka metode 'belajar dari pengalaman nyata' sebagai salah satu cara yang dapat dilakukan untuk memperkaya alternatif kebijakan guna menyelesaikan masalah yang ada. Begitu juga ketika dilihat dari perspektif komparasi pendidikan, membandingkan sistem pendidikan dengan negara lain harus melalui proses penelitian ilmiah seperti pada umumnya. Mungkin saja hasilnya lebih rigit dari pada ketika analis atau actor politis menelaah dengan metode 'belajar dari pengalaman nyata', namun hasil dari penelitian komparasi pendidikan pada akhirnya untuk memberikan masukan kepada actor politis untuk memformulasikan kebijakan.

\section{Hal-hal yang Mempengaruhi "Policy Borrowing"}

Perencanaan kebijakan mungkin nampak seperti proses administrative sederhana yang disusun oleh para birokrat. Faktanya perencanaan kebijakan, atau lebih sempit lagi ketika mengadopsi kebijakan luar, ternyata mengandung dinamika politik didalamnya. Terdapat actor-aktor yang terlibat dalam policy borrowing, baik actor yang berasal dari dalam maupun dari luar negara. Oleh karenanya, keputusan untuk meminjam kebijakan dari wilayah lain bukan perkara mudah. Philips (2006: 313) mengungkapkan bahwa "What has become known as policy 'borrowing' within the spectrum of transfer involves complex processes of adoption and adaptation..." (apa yang dipahami sebagai peminjaman kebijakan dalam spectrum transfer termasuk proses adopsi dan adaptasi yang kompleks). Kebijakan yang ditiru hanya akan menjadi bencana manakala tidak ada penyesuaian kritis dalam pelaksanaannya. Hal 
ini dikarenakan transfer kebijakan pendidikan bukan proses yang berdiri sendiri, melainkan sebuah spectrum yang didasarkan atas tingkat pengaruh lintas negara (Philips dan Schweisfurth, 2014). Spectrum tersebut terbagi dari yang bersifat voluntary sampai involuntary. Spectrum ini berjenjang bergantung pada seberapa besar pengaruh dari luar wilayah.

Pertama, transfer gagasan pendidikan yang ekstrim (seperti dalam pemerintahan otokratis yang menuntut filosofi baru dan norma-norma baru pasca perubahan situasi politik). Kedua, transfer kebijakan yang diperlukan namun 'dibawah tekanan' (misalnya dinegara yang dijajah, atau pascakrisis). Ketiga, transfer kebijakan yang 'dinegosiasikan di bawah paksaan' (seperti kondisi yang disyaratkan oleh lembaga atau negara donor dalam menerima bantuan mereka). Keempat, transfer pendidikan 'yang dipinjam dengan sengaja' (ketika pembuat kebijakan sengaja mengimpor ide dari tempat lain). Kelima, transfer kebijakan karena pengaruh umum dunia internasional atau globalisasi dalam hal penyebaran gagasan dan metode yang terkait. Kelima spektrum tersebut ditampilkan dalam gambar berikut

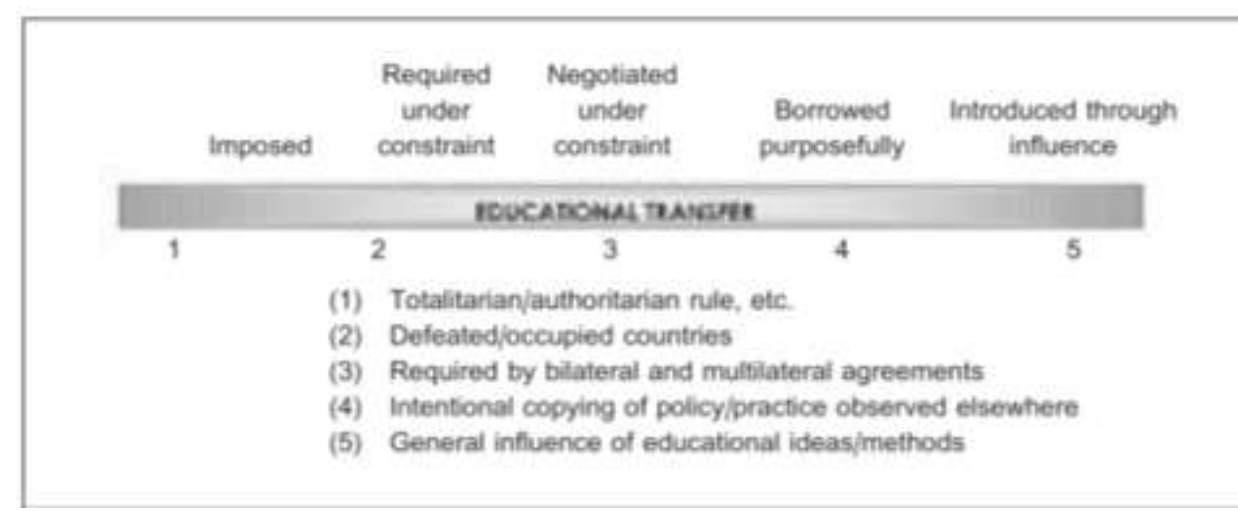

Gambar 1. Spectrum of Educational Transfer (Philips and Schweisfurth, 2014: 46)

Dalam literature yang sama, Philips menyampaikan ada tiga tahap simple educational transfer yakni identifikasi praktik sukses, memperkenalkan ke dalam konteks negara, dan asimilasi. Ketiganya peninggalan para comparativist yang ternyata rumit dengan banyak problem karena perbedaan latar belakang negara asal maupun banyaknya 
kepentingan yang berbeda. Proses yang terjadi dalam transfer kebijakan sangat kompleks, bahkan sejak zaman Antoine Jullien (Philips dan Schweisfurth, 2014).

Adanya daya tarik negara lain dan motivasi negara sendiri merupakan hal yang menggerakkan "home country" mengadopsi kebijakan dari wilayah lain. Namun, untuk menentukan keputusan borrowing maka variabel konteks menjadi penting untuk diperhatikan. Philips and Ochs (2003) menyatakan bahwa aspek politik, sosial, dan keagamaan, menjadi bagian factor yang berpengaruh terutama pada tahap pengembangan kebijakan untuk pengambilan keputusan.

Begitu juga Isaac Leon Kandel (dalam Arif Rohman, 2010: 55) menyatakan bahwa untuk membandingkan sistem pendidikan bukan hanya mencari persamaan dan perbedaan namun juga mencari penyebabnya karena Ia percaya teori kausalitas. Penyebab yang dimaksud disebut sebagai "national character" yang terdiri dari faktor statis dan dinamis. Faktor statis terdiri dari demografi, geografis, etnis, dsb. Sedangkan faktor dinamis seperti nilai-nilai modern, ide-ide sekuler, agama, dsb. Pandangan Kandel ini juga hampir sama dengan apa yang disampaikan oleh Michael Sadler (1990)

"in studying foreign system of education it should not be forgotten that things outside the school matter even more than things inside; and that an educational system is the outcome of (societal) forces which have been operated over an extended period of time"

Sadler memperjelas bahwa sistem pendidikan dan hasilnya di suatu wilayah tidak lepas dari sisi kesejarahan yang terbentuk dalam waktu yang panjang. Secara umum, kedua tokoh baik Kandel maupun Sadler sepakat bahwa mempelajari sistem pendidikan wilayah lain bukan hanya untuk melihat kulitnya saja, namun juga menggali factor yang melatarbelakanginya. Hanya saja, kritik disampaikan oleh Philips dan Ochs (2003) bahwa yang disebut "things inside" masih sulit diinterpretasikan. Meskipun demikian ia tetap sepakat bahwa konteks 
menjadi factor penting yang harus digali sebelum mengadopsi kebijakan dari luar lingkup wilayahnya.

Ekspektasi awal para policymaker ketika mengadopsi kebijakan yakni kesuksesan di wilayah lain dapat dicapai juga di wilayah sendiri. Namun, pada kenyataannya tidak selalu demikian. Menurut Dolowitz and Marsh (2000) ada tiga faktor yang berpengaruh terhadap kegagalan adopsi kebijakan. Pertama uninformed transfer, yakni ketidakcukupan informasi tentang kebijakan/institusi dan bagaimana kebijakan tersebut dijalankan di wilayah lain. Misalnya, negara Indonesia ingin mengadopsi kebijakan integrated curriculum dari Finlandia tetapi juga tidak boleh melupakan informasi tentang hasil adopsi kebijakan yang sama di negara lain. Mengkaji keduanya berarti informasi yang didapat lebih komprehensif. Kedua incomplete transfer, yakni tidak dijalankannya elemen penting yang membuat kebijakan di wilayah lain sukses. Misalnya melupakan peran penting birokrat garda depan dalam mengimplementasikan kebijakan, padahal mereka adalah orang-orang yang memahami secara langsung situasi permasalahan masyarakat. Ketiga inappropriate transfer, yakni kurangnya atensi terhadap perbedaan konteks ekonomi, sosial, politik, dan ideologi pada negara yang dipinjam. Pengabaian konteks ini akan lebih cepat menggiring pada kegagalan karena adopter tidak menggali atribut yang dapat mempengaruhi keberhasilan kebijakan yang diadopsi.

\section{SIMPULAN}

Seiring dengan perkembangan global, peminjaman kebijakan semakin massif guna perencanaan pendidikan tiap negara. peminjaman kebijakan merupakan kajian yang dapat ditelaah dari dua perspektif keilmuan, yakni ilmu kebijakan dan ilmu komparasi pendidikan. Policy borrowing dalam perspektif kebijakan digunakan sebagai salah satu metode yang disebut 'comparison of real-worlds experiences' (membandingkan dengan pengalaman nyata) untuk mengidentifikasi alternatif kebijakan. Sedangkan dalam perspektif ilmu komparasi pendidikan, policy borrowing merupakan 
tahap analitis yang lebih rigit sesuai metode ilmiah, meskipun hasil akhirnya tetap digunakan untuk rekomendasi perencanaan kebijakan. ketika meminjam kebijakan dari wilayah lain maka terdapat beberapa hal yang harus diperhatikan seperti akurasi informasi, kelengkapan elemen adopsi, dan ketepatan atensi terhadap konsteks wilayah.

\section{DAFTAR PUSTAKA}

A.G. Subarsono. 2013. Analisis Kebijakan Publik Konsep, Teori, dan Aplikasi. Yogyakarta: Pustaka Pelajar.

Anthony Chow. 2014. Replanting The Flower in Different Soil? A Critical Analysis of Education Borrowing in Hong Kong. International Journal of Education. Vol. 6. No. 2. pp. 114-127.

Arif Rohman. 2010. Pendidikan Komparatif: Menuju ke Arah Metode Perbandingan Pendidikan Antar Negara. Yogyakarta: Laksbang Grafika.

David P. Dolowitz and David Marsh. 2000. Learning from Abroad: The Role of Policy Transfer in Contemporary Policy-Making. Governance: An International Journal of Policy and Administration. Vol. 13. No. 1. pp $5-24$.

David Philips and Michele Schweisfurth. 2014. Comparative and International Education An Introduction to Theory, Method, and Practice $2^{\text {nd }}$ edition. London: Bloomsburry Academic.

David Philis and Kimberly Ochs. 2003. Processes of Policy Borrowing in Education: some explanatory and analytical devices. Comparative Education. Vol. 39. No.4. pp. 451-461.

Edmund James King. 1968. Comparative Studies and Educational Decision. United Kingdom: Routledge.

Gita Steiner-Khamsi and Florian Waldow. 2012. World Yearbook of Education 2012: Policy Borrowing and Lending in Education. United Kingdom: Routledge.

Manap Somantri. 2014. Perencanaan Pendidikan. Bogor: IPB Press.

Maria Fatima Bona. 2015. Mendikbud: SEAMEO, Ajang Mengadopsi Gagasan Pendidikan Negara Lain. diakses dari https://www.beritasatu.com/politik/322535/mendikbud-seameo-ajang- 


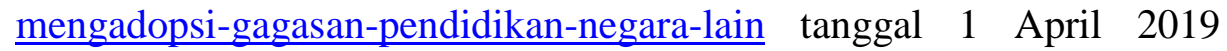
Pukul 05.21 WIB

Michael Sadler. 1900. How Far Can We Learn Anything of Practical Value From the Study of Foreign Systems of Education? England: Guildford.

Mulyo Prabowo. 2010. Pembelajaran di Sekolah: Harapan dan Kenyataan. Majalah Ilmiah Pembelajaran, Vol. 6. No. 1.

Nguyen Van Huy and M. Obaidul Hamid. 2015. Education Policy Borrowing In Globalized World. English Teacing: Practice and Critique. Vol. 14 Iss 1. pp 60-74.

Dominic Tierney. 2015. What America Can Learn From the Rest of the World https://www.theatlantic.com/international/archive/2015/10/clintonsanders-policy-world/412342/ diakses pada tanggal 1 April 2019 pukul $05.35 \mathrm{WIB}$ 